УДК 624. 042. 11

\title{
ИССЛЕДОВАНИЯ АДГЕЗИОННЫХ СВОЙСТВ КОМПОНЕНТОВ, ВХОДЯЩИХ В СОСТАВ 3С-3, И ИХ СООТНОШЕНИЯ
}

О.Г. Курс, С.В. Дмитрик, канд. техн. наук С.И. Возненко

ДОСЛІДЖЕННЯ АДГЕЗІЙНИХ ВЛАСТИВОСТЕЙ КОМПОНЕНТІВ, ЩО ВХОДЯТЬ ДО СКЛАДУ ЗС-3, ТА ЇХ СПІВВІДНОШЕННЯ

О.Г. Курс, С.В. Дмітрік, канд. техн. наук С.І. Возненко

\section{RESEARCH ADHESION PROPERTIES COMPONENTS INCLUDED IN THE 3C - 3 AND THEIR RELATIONSHIP}

\author{
O.G. Course, S.V. Dmitrik, cand. of techn. sciences S.I. Voznenko
}

Данная работа посвящена проблеме ремонта искусственных сооружений без использования тяжелой техники и без закрытия перегона. В ней использованы наработки по ремонту водопропускных труб под высокими насыпями. Ремонт осуществляется $c$ помощью мобильных бригад без предоставления окон. Рассмотрены несколько вариантов ремонта. Выбрана технология устройства металлической обоймы с закачкой за обделку СПЦВС и окраской составом 3С-3. Состав используется для ремонта различных поверхностей, в том числе и мокрых. Бетонные, каменные, металлические поверхности окрашивались составом. При этом адгезионная прочность на отрыв составляла не менее 2 Mna.

Ключевые слова: адгезия, мокрая поверхность, прочность, герметизачия, структура, нафталины, феноль, фракции, КУС, смола, молекуль, флокуль,, глобуль, когезия, разрушение.

Ця робота присвячена ремонту штучних споруд без використання важкої техніки та без закриття перегону. В ній використані напрачювання з ремонту водопропускних труб під високими насипами. Ремонт здійснюється за допомогою невеликих бригад без використання вікон. Розглянуто декілька варіантів ремонту. Вибрана технологія улаштування металевої обойми із закачуванням за обробку СПЦВС та покриттям $3 С-3$.

Склад використовується для ремонту різних поверхонь. зокрема вологих $i$ мокрих. Бетонні, кам'яні, металеві поверхні покривалися складом. При ц̧ьому адгезій на міиність на відрив складала не менше 2 Мпа.

Ключові слова: адгезія, мокра поверхня, мічність, герметизачія, структура, нафталини, феноли, фракиії, КУС, смола, молекули, флокули, глобули, когезия, руйнування

This article is dedicated to the problem of fiction buildings fix without using heavy technologies and closed area. The scientific researches under non-waterproof swallows with hight - hills were used in it. The main idea of this paper is to make a fix by mobile-groups without windows. Some variants of such a fix were under study. The choosen algorithm is as follocing : metal- shirt construction for SPCVS-methodics and PC-3 painting. This compound is used for different surfaces fix, the wet included. Broken- stone, metal surfaces were painted by this composition. When the process has been finished the adgesion was 2 Mpa. 
Keywords: adhesion, wet surface, strength, sealing, structure, naftalyny, phenols fraction of ASC, the resin molecules, floccules, globules, cohesion, destruction

В структуре КУС - ЭД различаются следующие структурные элементы:

- КУС - дисперсионная среда;

- глобулы ЭД - надмолекулярный уровень;

- агрегаты из глобул (флокулы) субмикроуровень.
В качестве основного прочностного показателя герметизирующего состава была принята величина адгезии к бетону M500. На рис. 1 представлена кривая зависимости адгезионной прочности 3С-3 от содержания КУС

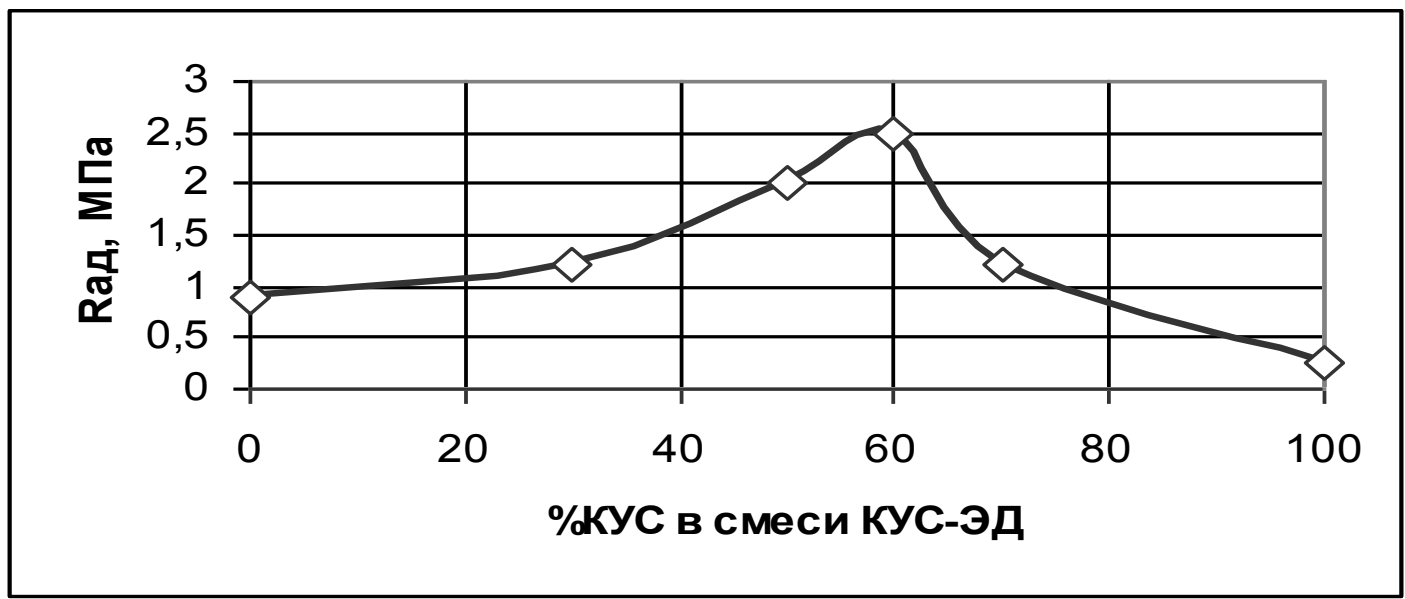

Рис. 1. Зависимость прочности адгезии состава КУС-ЭД от КУС

Как видим, график $\mathrm{R}_{\text {ад }}-\varphi_{\text {кус имеет }}$ экстремальный характер. Максимальная

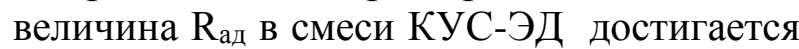

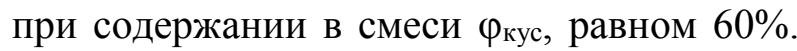
Объяснить проявление максимума $\mathrm{R}_{\text {ад }}$ при содержании КУС в смеси КУС-ЭД в количестве $60 \%$ можно следующим образом. Величину адгезии жидкообразного состава КУС-ЭД к твердой подложке можно выразить уравнением Дюпре

$$
\mathrm{W}_{\text {ад }}=\sigma_{ж г}(1+\cos \theta),
$$

где $\theta$ - краевой угол смачивания состава КУС-ЭД подложки;

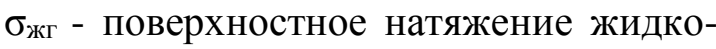
образного состава КУС-ЭД.

В то же время

$$
\sigma_{\text {жг }}=\mathrm{W}_{\mathrm{c}} / 2,
$$

где $\mathrm{W}_{\mathrm{c}}$ - работа когезии в смеси КУС-ЭД.
Подставляя, получим

$$
W_{a \partial}=\frac{W_{c}}{2}(1+\cos \theta),
$$

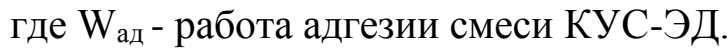

Дифференцируя (3) и учитывая, что при отрыве герметизирующего состава работа адгезии и когезии совершаются на одном и том же пути, уравнение (3) можно выразить через прочностные характеристики (1):

$$
R_{a d}=\frac{R_{c}}{2}(1+\cos \theta) .
$$

Следовательно, прочность адгезии состава 3С-3 к подложке определяется прочностью его когезии $\mathrm{R}_{\mathrm{c}}$ и краевым углом смачивания $\theta$ подложки при 
нанесении. Чем лучше смачиваемость, тем меньше угол $\theta$, тем больше величина $\cos \theta$ и тем выше адгезионная прочность. Экстремальный характер зависимости $\mathrm{R}_{\text {aд }}$

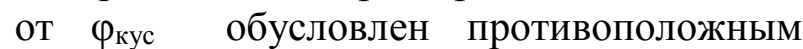
влиянием содержания КУС на когезию и на смачиваемость состава. При $\varphi_{\text {кус }}=0$ вязкость ЭД высокая, $\theta>90^{\circ}, \cos \theta-$ отрицательная величина и адгезионная прочность $\mathrm{R}_{\text {ад }}$ ниже $\mathrm{R}_{\mathrm{c}} / 2$. C увеличением Фкус понижается вязкость состава КУС-ЭД, увеличивается смачиваемость поверхности, величина $(1+\cos \theta)$ становится больше 1 , что вызывает увеличение $\mathrm{R}_{\text {ад при }} \varphi_{\text {кус }}=0-60 \%$.

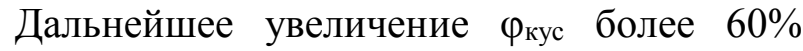
приводит к существенному уменьшению величины $R_{c}$ и на кривой $R_{\text {ад }}=f\left(\varphi_{\text {кус }}\right)$ наблюдается явный спад адгезионной прочности.

Следует отметить, что в соответствии c (3) величина $\mathrm{W}_{\text {ад }}$ стремится к $\mathrm{W}_{\mathrm{c}}$ для хорошо растекающихся жидких составов, когда $(1+\cos \theta=2)$, и при всех случаях $\theta$ не может ее превышать.

Формально влияние на $\mathrm{R}_{\text {ад }}$ смачивающей способности состава КУС-ЭД обусловлено более высокой энергией (прочностью) взаимодействия между КУС-ЭД и подложкой. В дополнение к этому существенное влияние на $\mathrm{R}_{\text {ад }}$ обеспечивает также механическое зацепление между этим составом и шероховатой поверхностью бетонной подложки. При этом более текучая смесь КУС-ЭД лучше затекает в микрокапилляры и микропоры поверхности, увеличивая при этом истинную площадь контакта и включение в $\mathrm{R}_{\text {ад }}$ дополнительных сил трения у стен этих пор и капилляров.

На основе наблюдений (1) величина прочности адгезии связана с величиной когезии исследуемого состава. С учетом этого содержание КУС до $80 \%$ в смеси КУС-ЭД приводит к структуре, у которой отсутствуют пластичные свойства. Поэтому целесообразно вести дальнейшие исследования участка от 80 до 60\% КУС.

Опытом установлено, что максимально возможное количество ЭД в таком составе составляет $30 \%$, т.е. при КУС/ЭД $=70 \%$. При более низком значении КУС/ЭД через некоторое время возникает недопустимое охрупчивание состава. При большем отношении КУС/ЭД смесь становится жидкообразной, теряя свои пластические свойства.

Дальнейшее модифицирование свойств герметизирующего состава осуществлялось путем добавления цементного наполнителя в смесь КУС-ЭД.

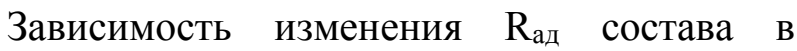
зависимости от содержания наполнителя (для цемента КУС-ЭД-Ц) $\varphi_{\Perp}$ в смеси КУС-ЭД представлена на рис. 2.

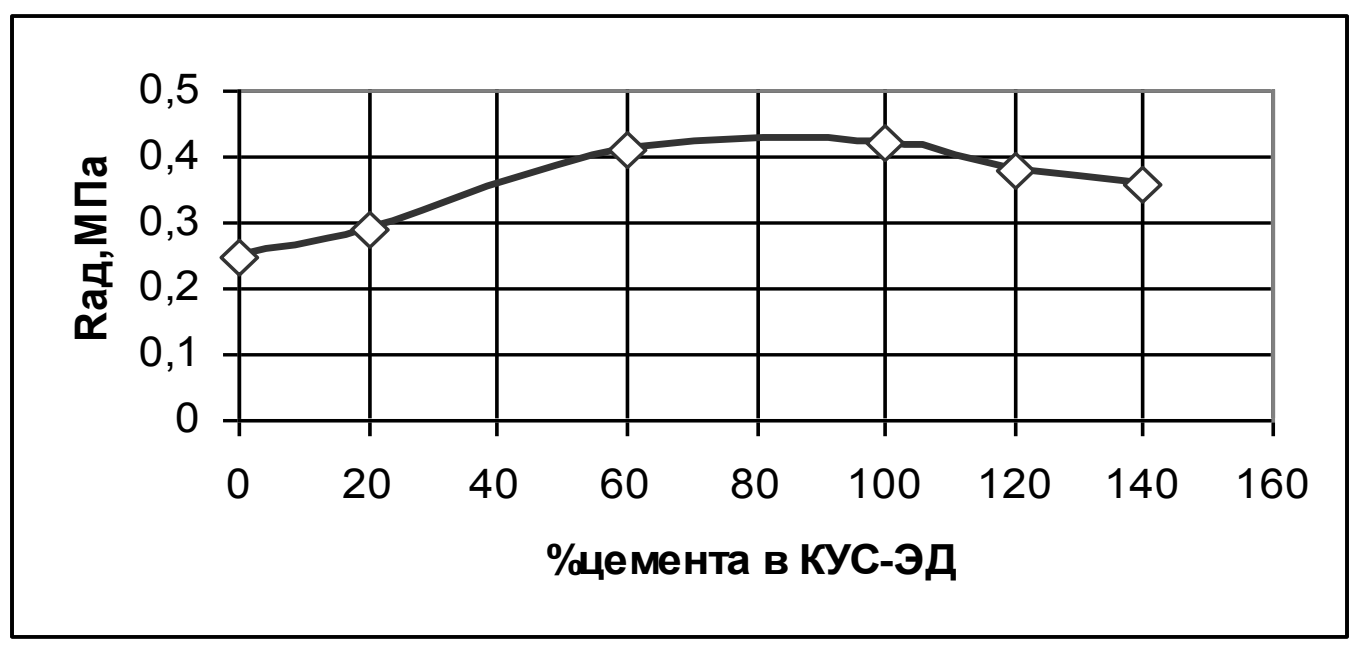

Рис. 2. Влияние количества цемента на адгезию 
Максимум $\mathrm{R}_{\text {ад }}$ при изменении $\varphi_{\Perp}$ можно также объяснить противоположным влиянием $\varphi_{\Perp}$ на когезионную прочность $\mathrm{R}_{\mathrm{c}}$ и растекаемость состава КУС-ЭД-Ц. При этом введение в смесь КУС-ЭД цемента, приводит к формированию структуры, состоящей из структурообразующих частиц цемента, соединенных через тонкие прослойки смеси КУС-ЭД. Такие прослойки будут упрочняться с уменьшением их толщины за счет направленного (ориентирующего) действия поверхности цементных частиц на структуру ЭД. Упрочняющее действие как показано в (1) поверхности цементных частиц с увеличением $\mathrm{R}_{\mathrm{c}}$ наблюдается на рис. 2 в интервале $\varphi_{\Perp}$ от 0 до $100 \%$.

Однако дальнейшее увеличение $\varphi_{\Perp}$ сверх $100 \%$ приводит к ощутимому влиянию загущающего эффекта, при котором увеличивается вязкость системы КУС-ЭД-Ц, увеличению $\theta$, соответственно уменьшению $1+\cos \theta$ и ухудшению смачивающей способности состава.
По данным графика (рис. 2) оптимальным наполнением цемента является отношение Ц/(КУС-ЭД) 100\%. Но при таком соотношении не обеспечивается необходимая вязкость (удобная для укладки защитного состава на подложку). Поэтому в качестве рабочего принимается состав КУС-ЭД-Ц при отношении Ц $($ КУС +ЭД $)=40 \%, \quad$ который принят в качестве рабочего для последующих испытаний.

Количество пека в КУС составляет $61 \%$, а жидкой фазы - $39 \%$. Согласно микрофотографии, полученной нами с помощью электронного микроскопа (рис. 3), средний размер структурообразующих частиц пека составляет 0,25 мкм. Более крупные образования - агрегаты (флокулы) из частиц пека. Толщину слоя масла вокруг частиц пека (принимаем сферической формы) определим ориентировочно из уравнения

$$
\frac{\frac{4}{3} \pi\left(R+\delta_{1}\right)^{3}-\frac{4}{3} \pi R^{3}}{\frac{4}{3} \pi R^{3}}=\frac{\gamma_{\varkappa \phi} \cdot m_{\kappa y c} \cdot \rho_{n}}{\rho_{\varkappa \phi} \cdot \gamma_{n} \cdot m_{\kappa y c}},
$$

где $\mathrm{R}$ - радиус частицы пека, м;

$\delta_{1}$ - толщина масляного слоя, м;

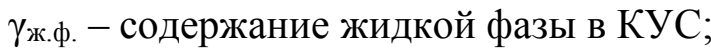

$\gamma_{\text {п }}$ - содержание частиц пека в КУС;

$\mathrm{m}_{\text {кус }}-$ масса КУС, кг.

Решая уравнение относительно $\delta$, получим

$$
\delta_{1}=\left(\sqrt[3]{\frac{\gamma_{\text {ж }} \cdot \rho_{n}}{\rho_{\varkappa \phi} \cdot \gamma_{n}}+1}-1\right) \cdot R .
$$

Подставляя известные данные для КУС $\left(\gamma_{ж \phi}=0,39 ; \gamma_{\Pi}=0,61 ; \rho_{\Pi}=1500 \kappa 2 / \mathrm{m}^{3}\right.$; $\left.\rho_{ж}=900 \kappa г / \mathrm{m}^{3}\right)$, получаем $\delta=0,034$ мкм $=$ $=340 \mathrm{~A}^{\mathrm{o}}$.
Толщина структурированного слоя $\delta$ у поверхности вискозиметра (рис. 3) составит:

$$
\delta=d_{n}+2 \cdot \delta_{1}
$$

$$
\delta=0,25+2 \cdot 0,034=0,32 \quad \text { (мкм). }
$$

Тогда вязкость при 60,40 и $20^{\circ} \mathrm{C}$ составит:

$$
\begin{aligned}
& \eta^{60}=8,8 \cdot 10^{-3} \mathrm{H} \cdot \mathrm{c} / \mathrm{s}^{2} ; \\
& \eta^{40}=17,6 \cdot 10^{-3} \mathrm{H} \cdot \mathrm{c} / \mathrm{s}^{2} \\
& \eta^{20}=61,7 \cdot 10^{-3} \mathrm{H} \cdot \mathrm{c} / \mathrm{m}^{2}
\end{aligned}
$$

В системе КУС образуется структура согласно (2), представленная на рис. 4. 


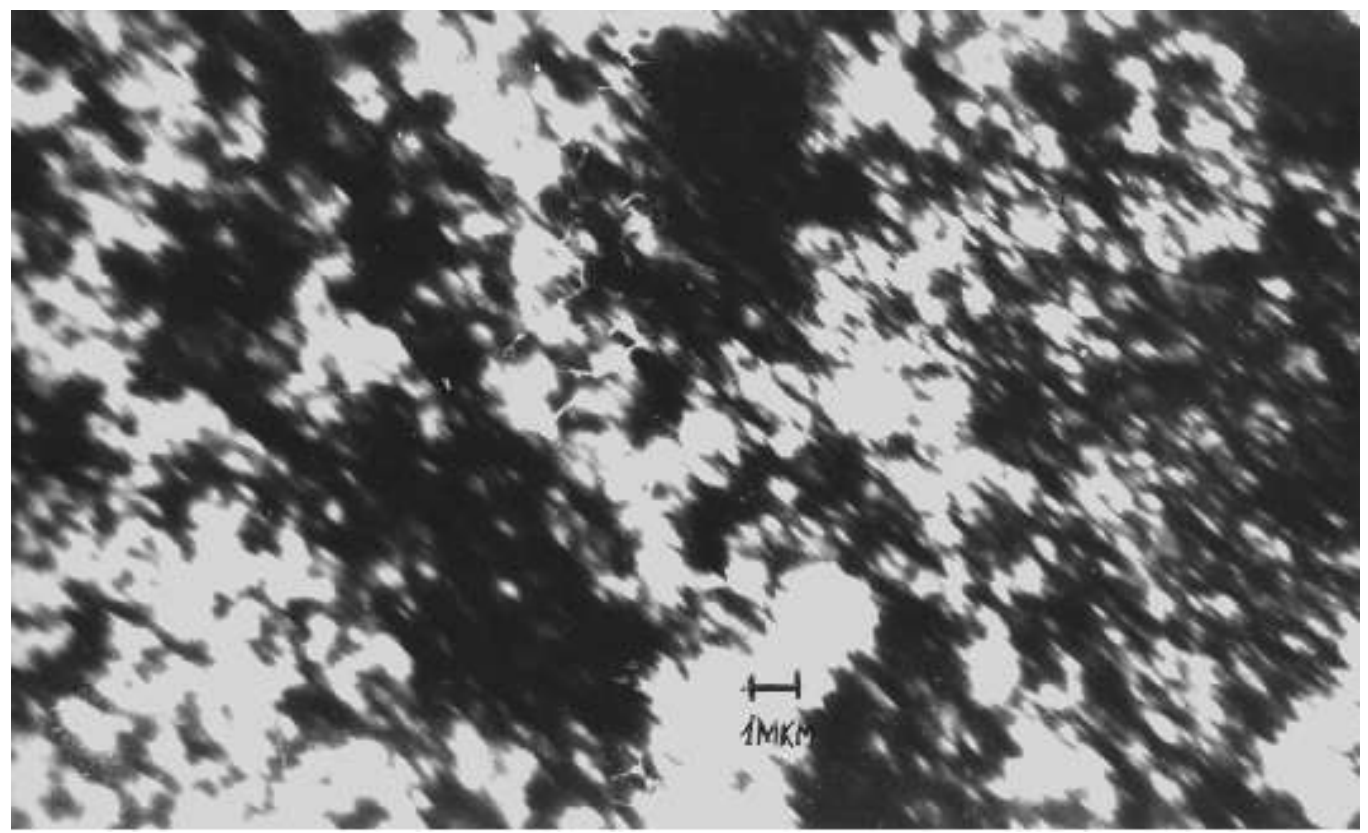

Рис. 3. Электронно-микроскопическая фотография КУС

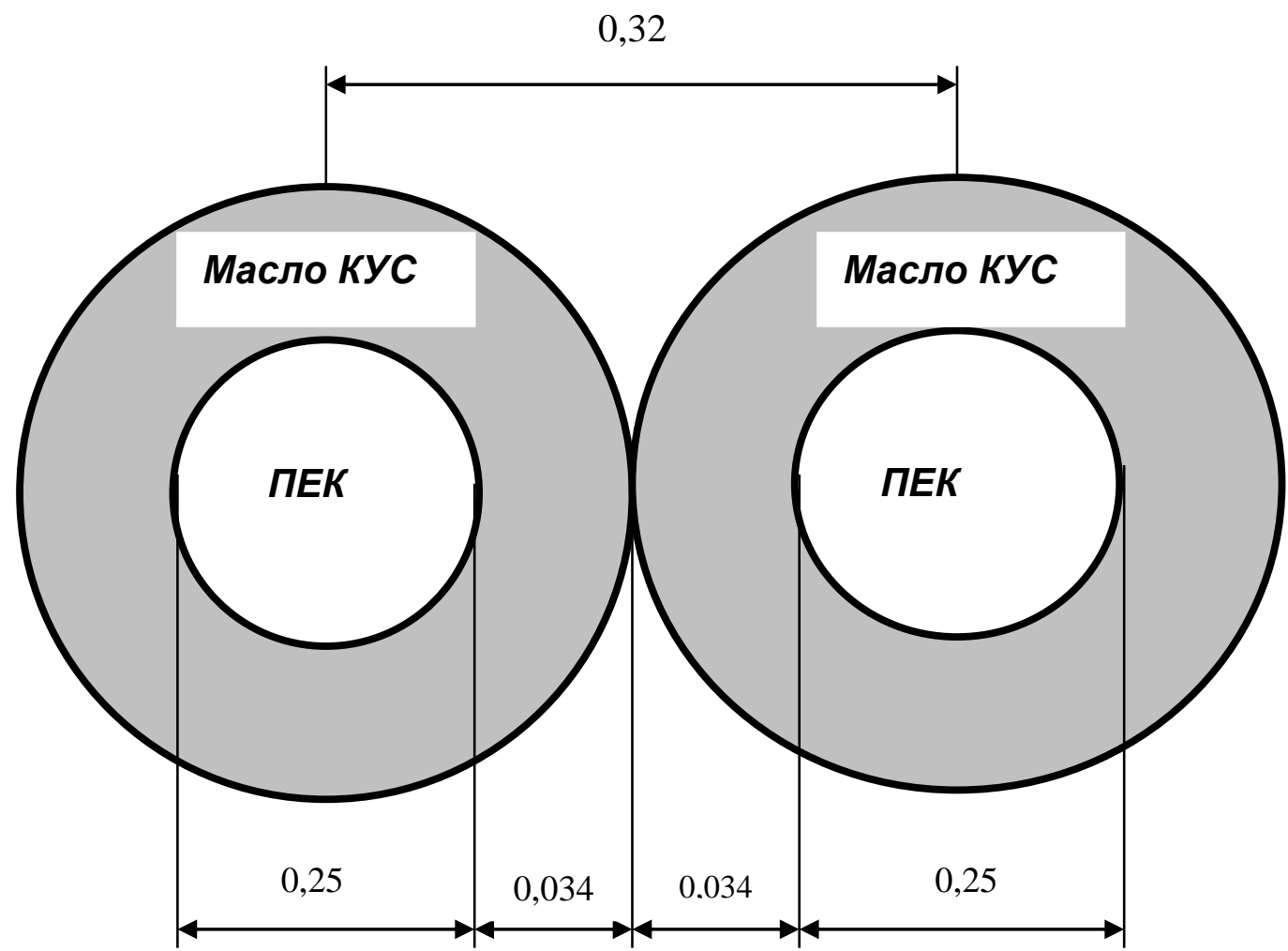

Рис. 4. Структура КУС как дисперсной системы

При введении в дисперсную систему КУС эпоксидной смолы (ЭД) увеличивается содержание дисперсной фазы за счет глобул и флокул ЭД. При этом за счет попадания флокул и глобул ЭД в структурированный пристенный слой вискозиметра происходит увеличение его толщины. Расчет $\delta$ для системы КУС-ЭД 
аналогичен расчету $\delta$ для КУС. Для системы КУС90-ЭД10 ( $\left.\rho_{\Pi}=1500 \kappa г / \mathrm{m}^{3}\right)$ толщина структурированного пристенного слоя составит:

$$
\delta_{1}=0,041 \cdot 10^{-6} \mathrm{M}=0,041 \mathrm{м \kappa м,}
$$

a

$$
\delta=0,332 \cdot 10^{-6} \mathrm{M}=0,332 \text { мкм. }
$$

Даже при незначительном введении ЭД в КУС (10\%) существенно увеличи- вается время истечения $\mathrm{t}$ смеси из вискозиметра, т. е. увеличивается условная вязкость смеси. Так, при $20^{\circ} \mathrm{C}$ время $\mathrm{t}$ увеличивается от 35 до 165 с. Это обусловлено связыванием более вязкой эпоксидной смолой частиц пека и возникновением дополнительной силы трения между скользящими слоями (рис. 5).

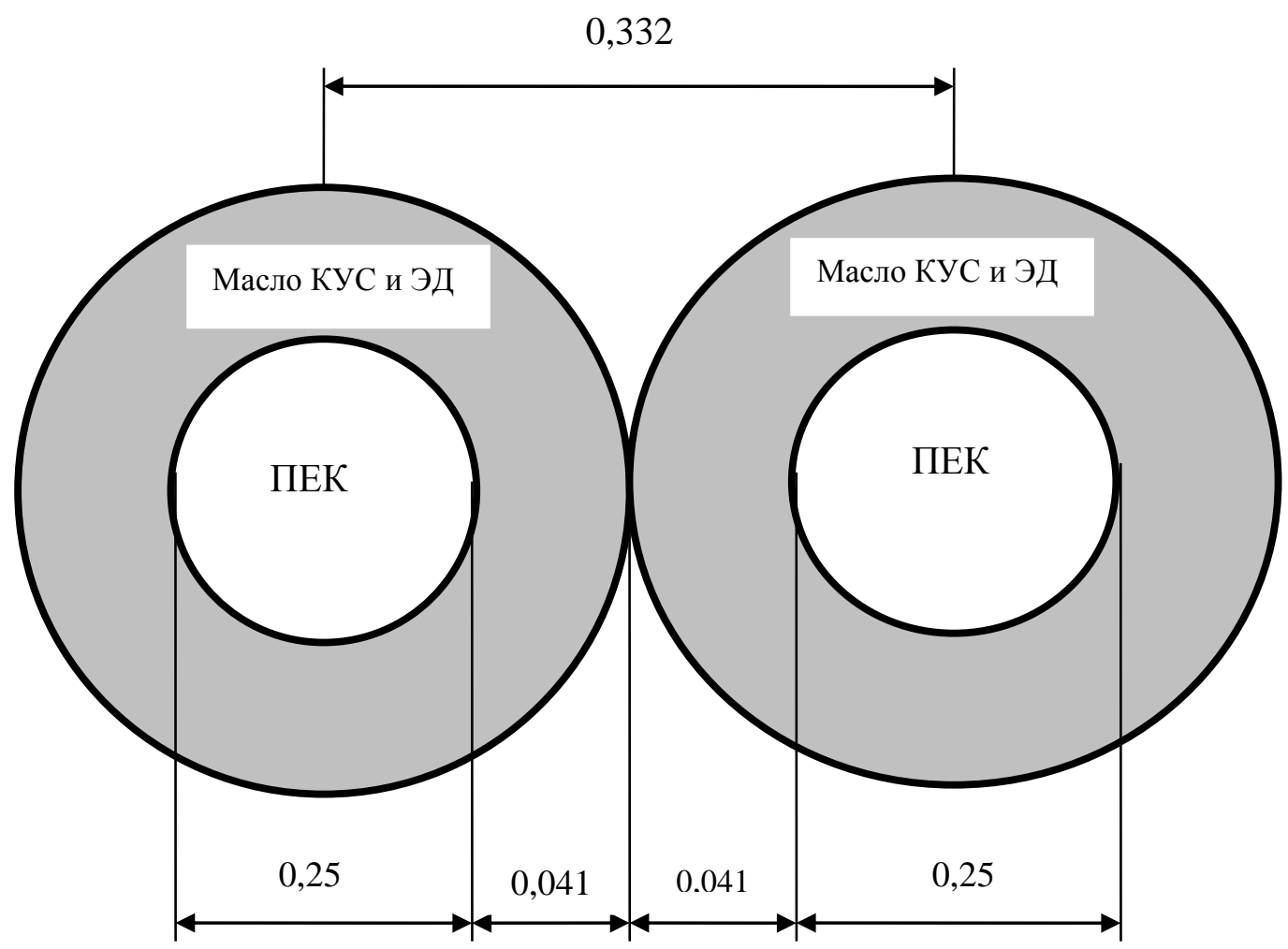

Рис. 5. Структура КУС-ЭД как дисперсной системы составит:

$$
\eta=302 \cdot 10^{-3} \mathrm{H} \cdot \mathrm{c} / \mathrm{m}^{2}=0,3 \mathrm{H} \cdot \mathrm{c} / \mathrm{M}^{2} .
$$

На рис. 6 представлен график изменения условной вязкости смеси КУС-ЭД-Ц (цемент), в дальнейшем композит, от изменения содержания цемента в ней.

По данным рис. 5 при содержании цемента менее $60 \%(\varphi<60 \%)$ в рассматриваемой композиции условная вязкость не изменяется. Это обусловлено

тем, что частицы цемента при их малом содержании находятся на расстоянии друг от друга, превышающем размер частицы, и это практически исключает эффект загущения дисперсной фазой. При увеличении содержания дисперсных частиц цемента свыше $60 \%(\varphi>60 \%)$ возрастает величина условной вязкости, что свидетельствует о значительном увеличении толщины структурированного слоя за счет размеров цементных частиц, входящих в этот слой (рис. 7). 
Залізничні споруди та колійне господарство

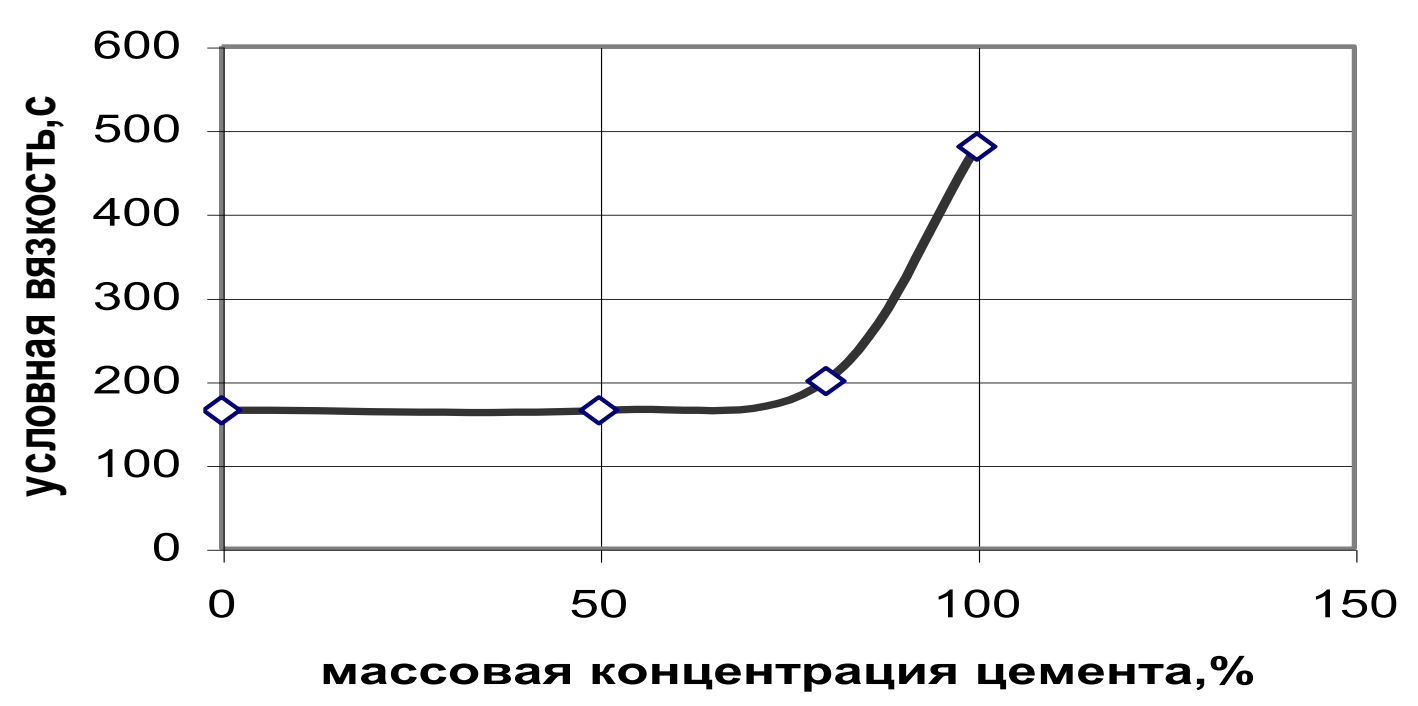

Рис. 6. Изменение условной вязкости дисперсной системы (КУС90-ЭД10-Ц) от содержания цемента

Оценку расстояния между внутренней поверхностью капилляра и ближайшего слоя цементных зерен определим по толщине прослойки между крупными частицами цемента, средний размер которых $\mathrm{d}_{\amalg}=30$ мкм. Принимая расположение цементных зерен на основе плотной кубической упаковки, получим выражение для коэффициента раздвижки частиц цемента:

$$
\lambda=\frac{V_{M}}{V_{n}}=\frac{(К У C+Э Д) / \rho_{\text {эд }}}{Ц / \rho_{u} \times \Pi y c m / \Pi_{Ц}},
$$

где $\mathrm{V}_{\mathrm{м}}$ и $\mathrm{V}_{\text {п }}$ - объем матрицы (КУС+ЭД) и объем пустот между частицами цемента при плотной кубической упаковке;

$\rho_{\iota}, \rho_{\text {эд }}$ - истинная плотность цемента и смеси ЭД-КУС, кг/м ${ }^{3}$;

Пуст - пустотность плотной кубической упаковки, 0,48;

$\Pi_{u}-$ абсолютный относительный объем цемента, 0,52.

Пуст. и П П определены расчетом для плотной кубической упаковки сферических частиц. Подставляя данные состава и значения: $\rho_{u}=3100 \mathrm{\kappa} 2 / \mathrm{m}^{3}, \rho_{\ni д}=1200 \mathrm{\kappa} 2 / \mathrm{m}^{3}$, получим $\lambda=4,46$. Средняя толщина прослойки между частицами цемента $\delta_{\text {п }}$ :

$$
\delta_{\Pi}=\left(\sqrt[3]{\frac{\lambda+1.1}{2.1}}-1\right) \times d_{u}
$$

Подставляя $\lambda$ и $\mathrm{d}_{\amalg}=30$ мкм, получим $\delta_{\text {п }}=15,8$ мкм. При таком составе смеси КУС-ЭД-Ц с $\delta=15,8$ мкм.

Расчеты и эксперименты показывают, что оптимальной по адгезии к поверхности (максимальная адгезия) и вязкости (минимальная вязкость) является смесь с величиной $\delta=15,8$ мкм, при которой между крупными частицами цемента (30 мкм) возникает прослойка, в среднем состоящая из двух рядов мелких частиц (6,4 мкм), окаймленных слоями из частиц пека. При этом все указанные частицы покрыты тонким слоем жидкой фазы КУСЭД.

При увеличении содержания цемента увеличивается плотность композиции по следующему выражению:

$$
\rho_{\kappa}=\frac{Ц+K У C+Э Д}{Ц / \rho_{Ц}+(К У C+Э Д) / \rho_{К У C+Э Д}}
$$


Величина объемной концентрации определяется по выражению

$$
\varphi_{\text {об }}=\frac{Ц / \rho_{u}}{(\kappa У C+Э Д) / \rho_{\text {КУС+эД }}},
$$

при $\varphi_{\text {об }}=39 \%$ плотность композиции составит $\rho=1730$ кг/ $\mathrm{M}^{3}$, а время истечения $t=480$ с. При этих значениях вязкость по формуле (4) составит $\eta=43,4 \mathrm{H} \cdot \mathrm{c} / \mathrm{M}^{2}$.

Эта величина близка к вязкости, определенной по прибору Ребиндера-Вейлера $\left(\eta=46,8 \mathrm{H} \cdot \mathrm{c} / \mathrm{m}^{2}\right)$, что свидетельствует о корректности определения величин $\delta$ и $\eta$ в указанных выше экспериментах.

Летучие вещества в значительном количестве содержатся в основном компоненте исследуемого защитного состава - каменноугольной смоле.

Основные характеристики летучих веществ, в том числе плотность и молекулярная масса, а также рассчитанные диаметры молекул приведены в таблице.

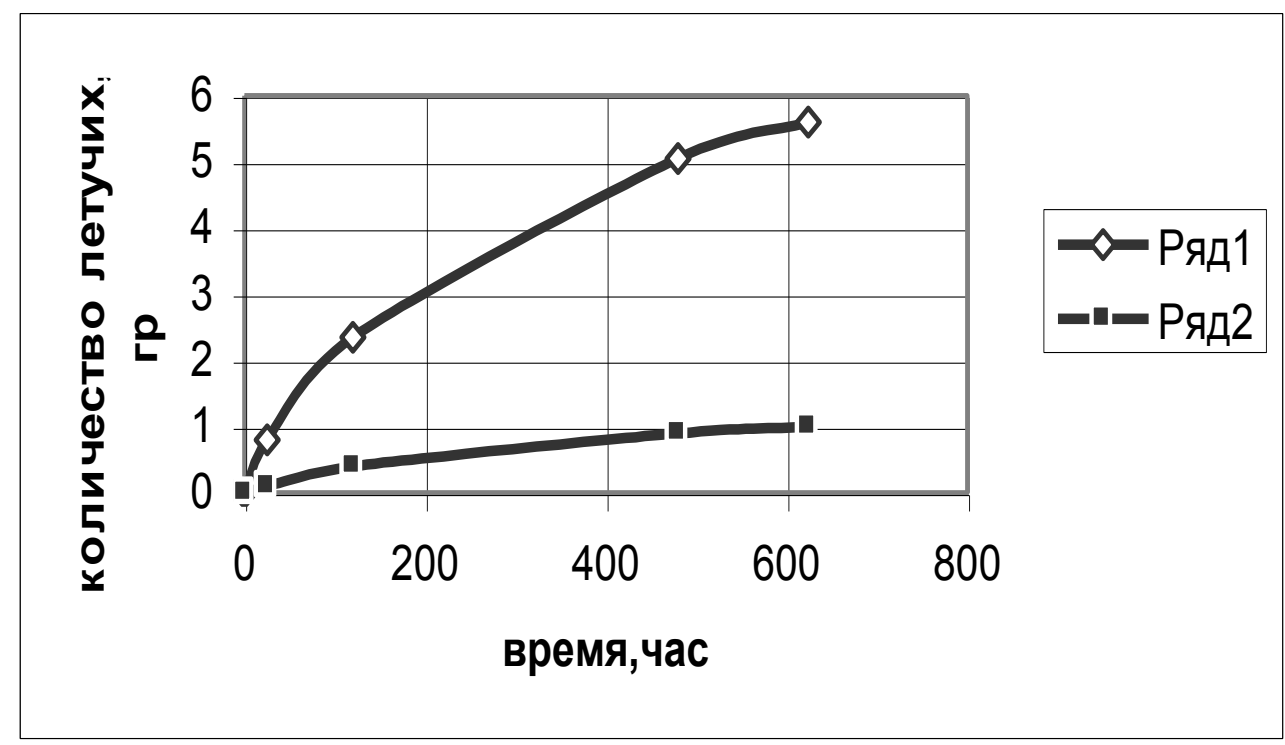

Рис. 7. Кинетика испарения летучих веществ из КУС: $1-$ при $60^{\circ} \mathrm{C} ; 2-$ при $20^{\circ} \mathrm{C}$

Характеристики основных летучих веществ в КУС

\begin{tabular}{|l|c|c|c|c|c|}
\hline \multicolumn{1}{|c|}{ Вещество } & $\begin{array}{c}\text { Плотность } \\
\text { при } 20^{\circ} \mathrm{C} \rho, \\
\Gamma / \mathrm{cm}^{3}\end{array}$ & $\begin{array}{c}\text { Молярная } \\
\text { масса M, } \\
\text { Г/моль }\end{array}$ & $\begin{array}{c}\text { Структурная } \\
\text { формула }\end{array}$ & $\begin{array}{c}\text { Содержа- } \\
\text { ние, \% }\end{array}$ & $\begin{array}{c}\text { Диаметр } \\
\text { молекулы } \\
\mathrm{A}^{\text {o }}\end{array}$ \\
\hline Бензол & 0,879 & 78,11 & $\mathrm{C}_{6} \mathrm{H}_{6}$ & & 5,3 \\
Толуол & 0,867 & 92,14 & $\mathrm{C}_{6} \mathrm{H}_{5} \mathrm{CH}_{3}$ & 2 & 5,6 \\
Ксилол & 0,864 & 106,17 & $\mathrm{C}_{6} \mathrm{H}_{4}\left(\mathrm{CH}_{3}\right)_{2}$ & & 5,89 \\
Нафталин & 1,168 & 128,18 & $\mathrm{C}_{10} \mathrm{H}_{8}$ & 10 & 5,7 \\
Аценафтен & 0,831 & 154,21 & $\mathrm{C}_{10} \mathrm{H}_{6}\left(\mathrm{CH}_{2}\right)_{2}$ & 2 & 6,7 \\
Фенол & 1,071 & 94,11 & $\mathrm{C}_{6} \mathrm{H}_{5} \mathrm{OH}$ & 2 & 5,3 \\
\hline
\end{tabular}


В состав КУС входит около 10 тыс. соединений, некоторые из которых являются летучими, например, бензольные (бензол, ксилол, толуол), нафталиновые и фенольные фракции. Для упрощения расчетов за основу приняты характеристики производных молекулы бензола.

Коэффициент диффузии определяется по формуле Эйнштейна

$$
D=\frac{R T}{6 \pi \eta r N},
$$

где $\mathrm{R}$ - универсальная газовая постоянная, 8,31 Дж/моль·град.;

Т - температура, К;

$\eta$ - вязкость, $\mathrm{H} \cdot \mathrm{c} / \mathrm{M}^{2}$;

r - радиус молекулы растворенного вещества, м;

$\mathrm{N}$ - число Авогадро, $6,02 \cdot 10^{23} 1 /$ моль.

Средний радиус молекул летучих определяем по кубическому объему, который занимает одна молекула. Этот объем в свою очередь определяется плотностью и молярной массой вещества по формуле

$$
\mathrm{Av}=\mathrm{M} / \mathrm{N}_{\mathrm{a}} \rho
$$

откуда

$$
r=0,5 \cdot d_{M}=\sqrt[3]{A_{v}}=\sqrt[3]{\frac{M}{N_{a} \rho}}
$$

Средний диаметр молекул составляет $d_{M}=(2 \cdot 5,6+10 \cdot 5,7+2 \cdot 6,7+2 \cdot 5,3) / 16=5,76 \quad A^{0}$.

В дальнейших исследованиях предполагается обезводить КУС, постараться выделить частицы пека и исследовать его структуру.

Можно предположить ,что его роль не сводится просто к роли наполнителя жидкой фазы КУС, а имеется дополнительный структурирующий эффект, основанный на сложных химических связях и влияющий не только на структурные свойства КУС, но и на весь состав 3С-3 в целом.

\section{Список использованных источников}

1. Возненко, С.И. Герметизирующие композиции на основе цемента и КУС для обводненных тоннелей [Текст]: дисс... канд. техн. наук / С.И. Возненко. - Харьков: УкрГАЖД, 1999. - 171 с.

2. Мирошниченко, С.В. Составы на основе цемента, КУС и высококачественных смол для герметизации и лечения трещин и швов [Текст]: дисс... канд. техн. наук / С.В. Мирошниченко. - Харьков: УкрГАЖТ, 1999. - 152 с.

3. Яковлева, Е.В. Прогнозировать деформации земляного полотна [Текст] / Е.В. Яковлева // Путь и путевое хозяйство. - 2005. - №6. - С. 29-32.

4. Коншин, Г.Г. Вибрационный метод диагностики насыпей [Текст] / Г.Г. Коншин // Путь и путевое хозяйство. - 2007. - № 10. - С. 22-25.

Рецензент д-р техн. наук, профессор А.А. Плугин

Курс Олег Геннадиевич, слушатель ИППК гр. МЗ-ЗС-Б-11.

Дмитрик Сергей Витальевич, слушатель ИППК гр. МЗ-3С-Б-11.

Возненко Сергей Иванович, канд. техн. наук, доцент кафедры пути и путевого хозяйства.

Course O.G., Dmitrik S.V., cand. of techn. sciences Voznenko S.I. 